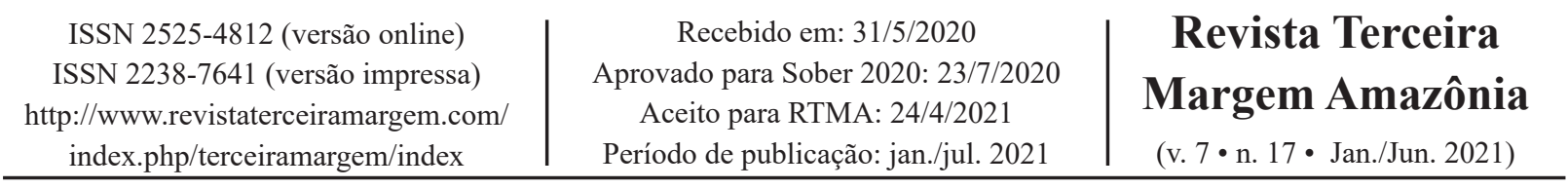

Como citar o artigo:

REIS, W. D. da S.; SILVA, S. J. M. Análise das teorias economia ecológica e a carta encíclica Laudato Si': sobre o cuidado da casa comum. Revista Terceira Margem Amazônia, v. 7, n. 17, p. 191-205, 2021. DOI: http://dx.doi.org/10.36882/2525-4812. 2021v7i17.p191-205

\title{
ANÁLISE DAS TEORIAS ECONOMIA ECOLÓGICA E A CARTA ENCÍCLICA LAUDATO SI': SOBRE O CUIDADO DA CASA COMUM
}

\author{
Willian Douglas da Silva Reis ${ }^{1}$ \\ Sidney Junior Martins da Silva ${ }^{2}$
}

\begin{abstract}
Resumo: O artigo analisa as contribuições da teoria econômica "Economia Ecológica" e da carta encíclica do papa Francisco "Laudato Si': sobre o cuidado da casa comum". A justificativa baseia-se na relevância de ambas as teorias para a conscientização ecológica mundial. Os objetivos específicos desta pesquisa são: descrever os pensamentos teóricos da economia ecológica e da carta encíclica papal e apontar os principais pontos semelhantes e distintos de ambas. A metodologia baseia-se no método comparativo. O método apresenta dez pontos semelhantes e somente a regulação da taxa de natalidade como pensamento distinto entre os autores. Com isso, verifica-se maior proximidade entre a corrente econômica e a carta encíclica do sumo pontífice. Vale ressaltar que a regulação de natalidade é o argumento crucial à economia ecológica, e o papa Francisco é contrário à opinião e fundamenta-se na frase do Pontifício Conselho "Justiça e Paz" (2010), de que o aumento da população é conciliável ao desenvolvimento íntegro e solidário.
\end{abstract}

Palavras-chave: economia ecológica, Laudato Si, sustentabilidade, regulação de natalidade.

\section{DINAMICS OF DEFORESTATION IN THE BRASILEIRINHO BRANCH, EAST ZONE OF THE CITY OF MANAUS, AM, IN THE YEARS 2008 AND 2017}

\begin{abstract}
The article analyzes the contributions of the economic theory "Ecological Economy" and the Encyclical letter of Pope Francis "Laudato Si': on the care of the Common House". The rationale is based on the relevance of both theories to global ecological awareness. The specific objectives of this research are: to describe the theoretical thoughts of Ecological Economics and the papal Encyclical Letter and to point out the main similar and distinct points of both theory. The methodology shall be based on the comparative method. The method presents ten similar points and only the birth rate regulation as distinct thinking among the authors. Thus, there is greater proximity between the economic current and the ency-

\footnotetext{
1 Economista, mestre em Economia, Cuiabá, MT. E-mail: willreis59@gmail.com

(D) https://orcid.org/0000-0002-0969-3419

2 Historiador, mestrando em História pela Universidade Federal de Mato Grosso (UFMT), Cuiabá, MT.

E-mail: sidneyjunior.martins@hotmail.com

(D) https://orcid.org/0000-0001-7755-5133
} 
clical letter of the Supreme Pontiff. It is worth mentioning that birthrate regulation is the crucial argument to the Ecological Economy and Pope Francis is contrary to the opinion and is based on the phrase of the Pontifical Council "Justice and Peace" (2010) that the population increase is compatible with the development of integrity and solidarity.

Keywords: ecological economics, Laudato Si, sustainability, birthrate regulation.

\section{Introdução}

Toda sociedade contém sua própria história, assim como tudo que existe na história: um fato que relata o passado, uma modificação em um espaço ou em determinado tempo. O meio ambiente também tem a sua trajetória. Se pararmos para pensar sobre os acontecimentos ecossistêmicos e observar os fatos atuais, verificamos uma série de mudanças climáticas e alterações na biodiversidade.

Catástrofes ambientais sempre aconteceram no mundo. Nos noticiários de telejornais, celulares e outros meios de comunicação, verifica-se algum acidente ambiental, seja uma enchente, um tsunami como aquele ocorrido na Tailândia em 2004, seja um terremoto no Nepal em 2015. No entanto, a percepção que se tem é que esses casos vêm em forma crescente. Mas esses acidentes ecológicos, que ocorrem com determinada frequência, têm interferência do ser humano? Segundo as mídias, as catástrofes estão em nível acelerado. As causas desses danos estariam ligadas ao desenvolvimento da sociedade?

Lesbaupin (2019) afirma que desde as últimas décadas as catástrofes ecológicas ocorrem crescentemente, por exemplo: inundações, secas, rios secos, calor acima da temperatura média, frio em excesso nos períodos de inverno e assim por diante. Nessa perspectiva, várias conferências, encontros e publicações acadêmicas relatam o antropocentrismo em relação à crise ecológica.

O filantropo industrial Aurelio Peccei, em 1968, elabora um estudo com a comprovação científica de que os danos ecológicos são em dimensão global (LAGO, 2013). Consoante com o livro $O$ valor da natureza: economia e política dos recursos naturais, de J. Aroldo Mota (2006), os resultados apresentados pelo filantropo são drásticos, ou seja, torna-se necessário uma mudança de comportamento dos habitantes do planeta em relação ao meio ambiente.

Em 1972, na Suécia, realizou-se a primeira conferência de países e agências governamentais em favor da natureza. Realizada em Estocolmo, essa primeira conferência sugere às organizações presentes o decrescimento industrial das nações desenvolvidas e a redução populacional das nações em desenvolvimento (NASCIMENTO, 2012). Santos (2018), em sua dissertação, relata o surgimento, em 1982, da Comissão Mundial do Meio Ambiente e Desenvolvimento da Organização das Nações Unidas (ONU), chamada de Comissão Brundtland, cujo objetivo era produzir um relatório sobre temas ecológicos especificamente nos padrões de produção e consumo em vigor.

Segundo Nascimento (2012), o tema busca o desenvolvimento da sociedade atual sem comprometer as necessidades e utilidades das gerações futuras. Nesse sentido, Lago (2013) comenta a criação da Conferência das Nações Unidas, em 1992, na cidade do Rio de Janeiro, com a pre- 
sença de 172 países, dos quais 108 mandatários de estado ou de governo, e 400 representantes de organizações não governamentais.

A Conferência Rio-92 produziu, de acordo com Mota (2006), uma nova visão sobre os desastres ambientais, ao comentar que as organizações também são culpadas pelos danos ocasionados ao ecossistema. Margot Wallstrom (2002), em seu discurso, apresenta à Cúpula de Joanesburgo o propósito de reafirmar as conclusões obtidas na Conferência Rio-92 e propõe habilidades de governança e uma relação sadia entre o meio ambiente e as nações.

Em 2008, ocorre a crise econômica mundial. Oliveira e Andrade (2012) salientam as evidências de uma mudança no sistema econômico para uma convivência harmoniosa com os limites do planeta. Em 2012, a Conferência Rio+20 acontece na cidade do Rio de Janeiro, em referência aos 20 anos seguintes da Rio-92. Em 2015, realiza-se o Acordo de Paris, que visa corresponder de forma global às ameaças climáticas com a contextualização do desenvolvimento sustentável e erradicar a pobreza (ADOÇÃO ACORDO DE PARIS, 2016).

Entre conferências e relatórios em defesa dos recursos naturais surgem também a corrente econômica economia ecológica e a carta encíclica do papa Francisco Laudato Si : sobre o cuidado da casa comum. Ambas são relevantes para a conscientização da sociedade em prol de preservação e conservação dos recursos ecossistêmicos.

O surgimento da economia ecológica dá-se a partir de 1988 com a criação da International Society for Ecologic Economics e, em 1989, com a criação da revista Ecological Economics para incentivar as produções acadêmicas voltadas à economia e ao ecossistema (CAMARGO, 2014). Ropke (2005) compreende que a corrente econômica aborda uma linha de pensamento heterodoxa, ou seja, ilustra uma visão econômica fora do convencional da economia por caracterizar os dinamismos da sociedade com pluralismo e transdisciplinaridade. Cavalcanti (2010) justifica a heterodoxia da economia ecológica ao relatar a economia humana como parte de um todo sublime, com a introdução das interações entre as ciências econômicas e ecológicas.

Posteriormente, em 2015, surge a carta encíclica do papa Francisco, Laudato Si': sobre o cuidado da casa comum, a primeira encíclica do papa contemporâneo, pois na encíclica Lumen Fidei quem inicia o texto papal é o papa Bento XVI (SILVEIRA, 2018). Rezende (2016) afirma que o nome da encíclica significa "Louvado Sejas", um cântico de São Francisco de Assis, e acrescenta que o papa inova ao escrever sua primeira encíclica em italiano, e não em latim, como de costume dos outros papas. Papa Francisco (2015) dedica a encíclica a São Francisco de Assis, por ser este o padroeiro dos estudantes e profissionais da ecologia, e escreve o texto não somente para os cristãos da Igreja Católica Apostólica Romana, mas também para todos os indivíduos da sociedade.

Diante do contexto, este artigo questiona quais são as contribuições da economia ecológica e da encíclica papal. A justificativa baseia-se na relevância da corrente econômica e do escrito do papa Francisco à conscientização mundial sobre a ecologia. O objetivo geral deste artigo é analisar as contribuições teóricas da economia ecológica e da carta encíclica Laudato Si': sobre o cuidado da casa comum; os objetivos específicos são: descrever os pensamentos teóricos da economia ecológica e da carta encíclica papal e registrar os principais pontos semelhantes e distintos entre ambas as teorias observados pelos autores deste texto. 
A metodologia fundamenta-se no método comparativo, que confronta e reflete pontos semelhantes e distintos da economia ecológica e da encíclica Laudato Si': sobre o cuidado da casa comum. Graças a esse método, encontram-se dez pontos parecidos e um ponto diferente entre elas, ou seja, os pensamentos são mais próximos do que distantes, e somente a regulação de natalidade os distingue.

O artigo é composto pelas seções: introdução, que contextualiza a realidade ecológica e apresenta os temas relevantes do texto, que são: economia ecológica, com a descrição da corrente econômica, e a carta encíclica Laudato Si': sobre o cuidado da casa comum, com os principais pontos teóricos do texto do Papa Francisco; a metodologia do artigo, com o método comparativo, os pontos teóricos semelhantes e distintos da economia ecológica e da encíclica Laudato Si'; e as devidas conclusões.

\section{Economia ecológica}

A economia ecológica é uma corrente econômica que visa compreender os processos econômicos por meio da ecologia. Por isso, esta seção apresenta os principais conceitos e pensadores e discute se realmente as catástrofes ecológicas são de origem antropológica. Caso a hipótese seja verdadeira, necessita-se de mudança de comportamento perante a sociedade para o futuro da humanidade.

Costanza et al. (1991) declaram que a economia ecológica é uma ciência multi e transdisciplinar por englobar diversas disciplinas distintas, como as ciências econômicas, sociais, naturais e políticas, sem apresentar, no entanto, um peso maior para uma ciência perante a outra, pelo fato de a realidade manifestar problemas multidimensionais. Martinez-Allier (2015) resume economia ecológica como uma área que visa a economia como um subsistema de algo maior e finito, denominado de ecossistema.

Segundo Cechin e Veiga (2010), o principal pensador da corrente econômica é o romeno Georgescu-Roegen, com formação em matemática e estatística, postulante a economia com o economista Joseph Schumpeter, em Harvard, entre os anos 1934 e 1936. A relevância dos estudos do romeno à economia era tão grande, de acordo com os autores, que Paul Samuelson, em 1966, no prefácio do livro Analytical Economics refere-se à Georgescu-Roegen como o "professor dos professores" e "economista dos economistas". No entanto, 10 anos depois, Samuelson bane o "economista dos economistas" da comunidade econômica na edição do livro Economics.

A justificativa de Georgescu-Roegen (2008) para o ato de Samuelson envolve a crítica do modelo mecânico da teoria neoclássica. $\mathrm{O}$ autor utiliza a metáfora de que a economia convencional é um carrossel com nenhuma hipótese de comover o ambiente formado por matéria e energia, ou seja, o "economista dos economistas" incorpora a economia dinâmica ao modelo, caso recusado pelos economistas dominantes.

O autor fundamenta a economia ecológica na Segunda Lei da Termodinâmica ou Lei da Entropia. Entropia origina-se do grego e significa transformação (CLAUSIUS, 1865). GeorgescuRoegen (2008) presume a Lei da Entropia, em que a energia não se transforma em trabalho no decorrer do processo, mas uma parte dissipa em calor. 
Figura 1. Visão da economia ecológica.

\section{Modelo Biofísico do Sistema Econômico (fluxos de matéria e energia)}

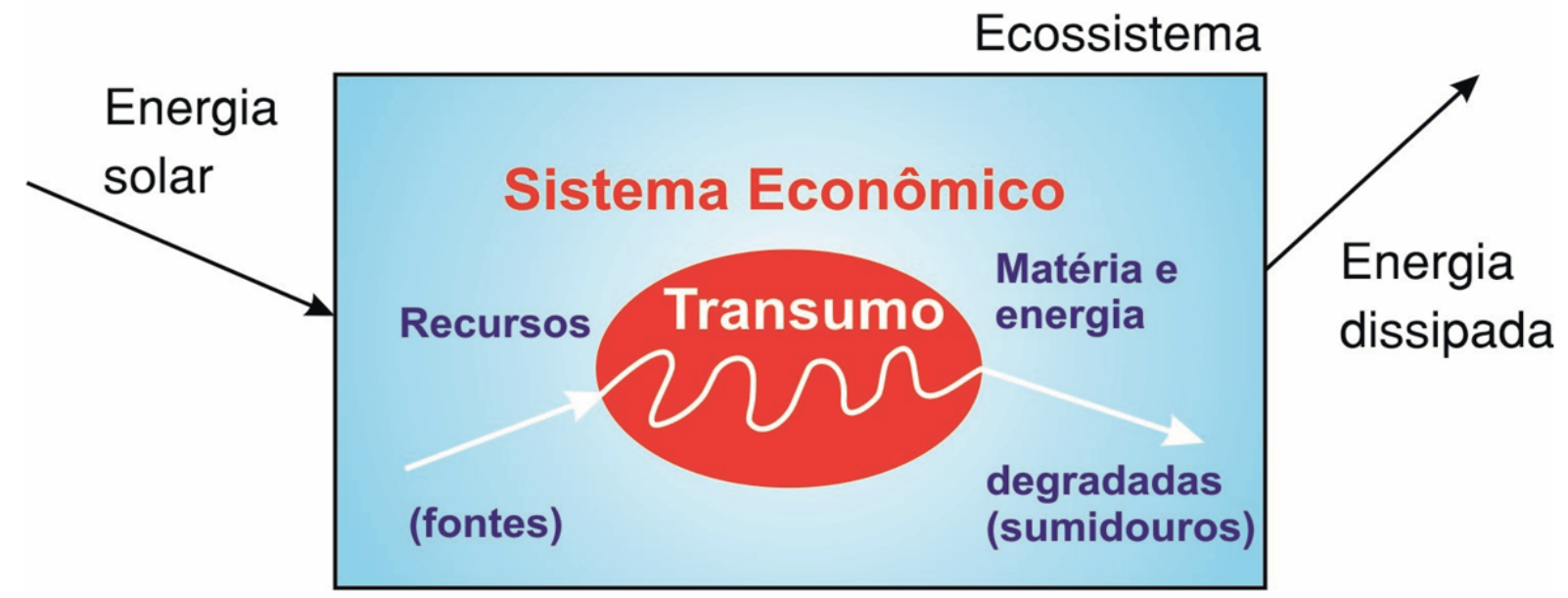

Fonte: Cavalcanti (2010).

A Figura 1 ilustra a atividade econômica do sistema aberto do ecossistema. May (2010) define os sistemas abertos como sistemas que transferem matéria e energia para a natureza, caso da economia. Cavalcanti (2010) explica que a matéria e a energia adentram o sistema econômico e atravessam o processo de "transumo" para posteriormente tornarem-se lixo ou resíduo.

May (2010) especifica a Lei da Entropia ao comentar que parte do calor não é reaproveitada em plenitude e dissipa tendencialmente, mesmo o calor sendo distribuído uniformemente. Com isso, o autor conclui o pensamento ao apresentar os conceitos de baixa e alta entropia. A baixa entropia acontece quando as energias e as matérias são proveitosas; a alta entropia caracteriza-se na dissipação das energias e das matérias devido à manutenção da organização do sistema. Georgescu-Roegen (1971) afirma que a economia realiza a baixa entropia de energia e matéria e produz subprodutos de resíduos com a alta entropia.

Nesse âmbito, Romeiro (2014) conceitua resiliência como a capacidade de o ecossistema voltar ao estado nativo após uma mudança de perturbação ambiental. Vale ressaltar que quanto menor o tempo de reestabelecimento, maior é a resiliência encontrada no ecossistema. Veiga (2010) acrescenta a relevância da manutenção das atividades e ordenação do sistema para reagir aos choques e alterações.

May (2010) considera o tempo como uma variável importante para a análise econômica, em que o calor dissipado apresenta uma relação somente com o tempo e torna inerente a transformação de energia. $\mathrm{O}$ autor considera que o sistema produtivo transforma os recursos naturais em produtos dos quais a sociedade usufrui e produz um determinado resíduo, que não retorna para a cadeia produtiva devido às fases temporais. 
Leff (2004) demonstra o sistema produtivo não apenas teoricamente, mas enumera exemplos, como as taxas crescentes de desaparecimento ecológico, de extermínios de ecossistemas de conservação e da biodiversidade, regeneração das fontes renováveis, poluições terrestres, aéreas e marítimas e ameaças provenientes do aquecimento global. Para solucionar os problemas descritos, a economia ecológica apresenta as seguintes soluções para o processo econômico: "Economia do Astronauta", "Decrescimento Econômico" e "Nível de Estado Estacionário", com os respectivos criadores: Kenneth Boulding (1966), Nicholas Georgescu-Roegen (2008) e Herman Daly (1991).

Quanto à primeira solução, Boulding (1966) acredita que a economia não está associada ao crescimento de produção e de consumo, contudo associa-se às alterações tecnológicas que demonstram resultados nos estoques de capital com a diminuição do uso de recursos naturais. $\mathrm{O}$ autor comenta que o entendimento da humanidade sobre a finitude dos recursos naturais é recente, assim o sistema torna-se fechado para os bens materiais, mas com livre entrada e saída de energia, e teria semelhança com uma nave espacial, por isso a visão dita "economia astronauta".

A segunda solução surge no livro de Georgescu-Roegen (2008), com a afirmação de que o crescimento não deve ser crescente, mas o inverso do crescimento, ou seja, de acordo com as pesquisas apresentadas pelo Clube de Roma, em 1972, a espécie humana entrará em coma nas próximas gerações, e a solução para perpetuação da espécie é uma economia decrescente.

Latouche (2009) reforça o pensamento de uma mudança cultural da sociedade, na qual a crença de crescer por crescer economicamente seja negada, e ressalva que a proposta não é idealista, mas uma realidade possível. Saes (2013) e Van den Bergh (2011) adicionam ao decrescimento a redução de escala da economia, a diminuição da dimensão física da economia, redução do Produto Interno Bruto (PIB) dos países, restrição ao consumismo ou horas de trabalho e alteração radical dos aspectos econômicos, como os valores, a ética dos mercados e a função da moeda e trabalho.

A terceira solução surge desde os economistas clássicos, como: John Stuart Mill (1920), ao afirmar que o estado estacionário é a salvação ecológica da humanidade; Robbins (1930), ao comentar sobre a especificação dos idealizadores do estado constante de crescimento econômico; e David Ricardo (1951), ao relatar que a condição estacionária somente iria ocorrer com a pressão popular por causa de alimentos. Porém, somente Herman Daly (1991) especifica a definição do estado estacionário detalhadamente, uma economia com estoque de pessoas e dispositivos constantes, com desejáveis níveis de bem-estar e baixo nível de fluxo de energia e matéria desde a etapa inicial de produção até a etapa final de consumo.

Com isso, a economia ecológica confirma a hipótese de que as catástrofes ecológicas são consequências das ações humanas no processo econômico, e os principais autores exigem uma alteração de comportamento para que a humanidade não sofra sérios danos futuros.

A próxima seção do texto descreve o pensamento do papa Francisco na encíclica Laudato $S i$ ': sobre o cuidado da casa comum, um escrito posterior ao Acordo de Paris e de relevância para a sociedade (SILVEIRA, 2018). O conceito central é a ecologia integral e suas dimensões, o qual Murad (2017) compreende como um desafio extenso e articulador para que a sociedade global 
concretize o conceito do sumo pontífice. Por isso, a primeira encíclica do papa Francisco é motivo de estudos na academia.

\section{“Laudato SI': sobre o cuidado da casa comum}

A primeira carta encíclica publicada do papa Francisco surpreende a humanidade ao falar minimamente de Jesus Cristo, o Salvador, e declarar a importância de se preservar e conservar os recursos ecossistêmicos do planeta. Devido a essa realidade, alguns cristãos ficaram espantados com a verdadeira intenção do sumo pontífice, que é a de assemelhar-se à imagem de São Francisco de Assis. Seria o papa Francisco um São Francisco de Assis do século XXI?

A encíclica Laudato $S i$ ': sobre o cuidado da casa comum é composta por 246 parágrafos, formada por seis capítulos, com o tema central ecologia integral, o primeiro registro de um pontífice dedicado ao tema (THOMASSET, 2019). Tavares (2019) analisa que o sucessor de São Pedro alcança uma crítica relevante e particular sobre a organização entre o conhecimento abordado e o discurso apresentado.

A nomenclatura da encíclica é um cântico de São Francisco de Assis, cujo significado é "Louvado Sejas", recordando a terra como nossa irmã, a que nos ampara, administra e entrega diversos frutos (PAPA FRANCISCO, 2015). O papa expõe que cada cidadão da sociedade causa danos ecológicos, cometendo um pecado contra si mesmo e contra Deus. Francisco pede proteção a nossa casa comum e que, em família, adquiramos o desenvolvimento sustentável e integral.

O primeiro capítulo da carta é sobre os acontecimentos do planeta, objetivando obter uma sofrida consciência para transformar o indivíduo, levando-o a contribuir para a humanidade. Os primeiros tópicos do capítulo demonstram a crise ambiental ocasionada por poluição e mudanças climáticas. Fala também da falta de água, principalmente nas regiões necessitadas, diminuição da biodiversidade, depravação social e deterioração planetária; por fim, o capítulo apresenta, nos dois últimos tópicos, um relato da falta de cultura para enfrentar a crise ecológica e a necessidade de ter autoridades que apontem o caminho de saída e, assim, a esperança de uma sociedade sem degradação do planeta.

Nesse contexto, o segundo capítulo contribui com a teologia judaico-cristã da criação, ou seja, recorda passagens bíblicas, em especial o livro de Gênesis, capítulo 2, versículo 15. O papa traz o conhecimento hermenêutico do homem em cultivar e guardar o jardim do Éden (BÍBLIA..., 2015). Nesse sentido, a palavra cultivar significa que o homem deve trabalhar e guardar, deve preservar a riqueza oriunda do Criador. Com isso, o papa Francisco (2015) menciona fundamentos trinitários teológicos: a terra como dom de Deus para a humanidade, o Evangelho convoca os cristãos a viver segundo os passos de Cristo e o Espírito Santo, que santifica os fiéis e os leva a caminhar horizontes desconhecidos.

O terceiro capítulo desenvolve "a raiz humana da crise ecológica" com o paradigma tecnocrático predominante e o espaço que ele ocupa nos indivíduos e sobre as atividades dos seres humanos. Tavares (2019) afirma que o sumo pontífice não é uma pessoa contra a modernidade, pois reconhece os prodígios fornecidos pelo instrumento em prol das melhorias do bem-estar social, porém demonstra os interesses finais da tecnociência, que restringe a vida em suas dimen- 
sões e manifestações. Thomasset (2019) acrescenta o pensamento do papa ao abordar as falhas do coração, sendo o ego exagerado, a indiferença com o próximo e o homem centro do universo.

O quarto capítulo é o conceito principal do escrito, no qual o sucessor de São Pedro desenvolve os princípios da ecologia integral, sendo a ecologia ambiental, econômica, social, cultural e vida diária e a inclusão dos princípios de bem comum e a justiça entre as gerações. Papa Francisco (2015) define ecologia como ciência que estuda os vínculos entre os organismos vivos e o ambiente onde evoluem. O sumo pontífice ressalva que a sociedade está interligada com os componentes naturais, e o meio ambiente é a conexão entre a natureza e o corpo social que reside.

Posteriormente, o papa afirma que não existe uma crise somente do meio ambiente ou social, mas uma crise socioambiental, e as soluções para combater a crise requerem um pensamento integral para conflitar a pobreza, restituir a dignidade dos isolados e preservar a natureza. Em contrapartida, o crescimento econômico cria necessidade de proteger o ecossistema, a ecologia social deve agir dentro das instituições e progredir em distintas dimensões, desde o âmbito da família aos órgãos internacionais, a ecologia cultural integra os aspectos históricos, culturais e arquitetônicos da localidade, com respeito à tradição local, e a ecologia da vida diária origina na análise dos espaços onde os indivíduos decorrem o seu tempo.

No final do capítulo, o autor aborda os princípios do bem comum e da justiça entre as gerações. O papa entende como bem comum o respeito pelo ser humano, por seus direitos essenciais, e que não podem ser transferidos para outros. Ao se referir a direitos, o sumo pontífice cita a segurança, o bem-estar social, a paz social e o desenvolvimento de diversas camadas intermediárias, em especial a família. A justiça entre as gerações engloba o direito de não excluir os indivíduos que virão nas próximas oportunidades, pois o planeta pertence também àqueles que ainda irão nascer.

No quinto capítulo, o papa Francisco (2015) apresenta os diálogos entre: o meio ambiente na política internacional, as recentes políticas locais, a transparência nos mecanismos de decisão, a política e a economia, as religiões e a ciência. O sumo pontífice descreve diálogo do meio ambiente e a política internacional como a interdependência das nações, porém estas não são isentas das responsabilidades com o meio em que vivem e as obrigam a uma perspectiva comum para um único planeta. O diálogo recente das políticas locais enfatiza a relevância do Estado em assumir as devidas responsabilidades sobre a sua territorialidade e realizar trabalhos em longo prazo.

O diálogo em transparência nos mecanismos de decisão exige a inclusão de princípios interdisciplinares, sem considerar as pressões políticas e econômicas. O diálogo entre a economia e a política é frisado pelo pontífice, nenhum é superior ao outro, pois a superioridade causa danos irreversíveis, principalmente aos pobres, assim a unidade entre ambos é superior. O diálogo entre as religiões e as ciências demonstra que sozinhas não explicam tudo, mas a solução técnica é movida por conhecimentos éticos, como a convivência entre os povos, o sacrifício e a bondade.

No sexto capítulo da encíclica, o papa Francisco (2015) ressalva a importância da sociedade em mudar de atitude perante a casa comum, o sentimento de pertencimento ao planeta e a reflexão sobre o futuro das novas gerações. O papa opta por abordar o capítulo em nove tópicos, sendo eles: a mudança de estilo de vida; a relevância da educação ambiental; o propósito de conversão interior à crise ecológica; a valorização dos pequenos atos e atitudes cotidianas; a impor- 
tância dos atos de amor; a riqueza dos sacramentos para transformar a natureza em sobrenatural; a relação entre a Santíssima Trindade e a natureza como ato interligado; pedido de ajuda e proteção a São José e Santa Maria; e, por fim, a vida eterna para louvar a Deus.

Em conformidade com a carta encíclica do papa Francisco, verificam-se duas realidades: o desejo do atual papa de retornar aos temas considerados importantes por São Francisco de Assis e o conceito chave da escrita, que é ecologia integral. Ao contrário do que alguns cristãos pensam, o sumo pontífice revela o interesse de ser o santo padroeiro dos animais e da humildade, mesmo em contextos históricos distintos. $\mathrm{O}$ fato pode desagradar uma parte da população mundial, porém é de extrema relevância o líder religioso revelar a sua preferência a favor dessa causa tão humana e contemporânea.

Posterior a essa seção, o estudo aborda a metodologia adotada pelo artigo. O método escolhido é o comparativo, método utilizado desde a Antiguidade, cuja finalidade é construir conhecimento e analisar as teorias. O objetivo central desse método é comparar e refletir sobre os pontos semelhantes e distintos da economia ecológica e da Laudato Si': sobre o cuidado com a casa comum.

\section{Metodologia}

Após demonstrar os principais conceitos e pensamentos da economia ecológica e da encíclica papal Laudato Si': sobre o cuidado da casa comum, do papa Francisco, os autores desenvolvem o método comparativo das ciências sociais. Segundo León e Garza (2014), desde Aristóteles o método comparativo é usado na ciência com a finalidade de comparar os procedimentos e teorias da investigação científica.

De acordo com Assis (2009), o método comparativo investiga as semelhanças e as diferenças entre grupos, pessoas, teorias e outros. Conforme Schneider e Schmitt (1998), a comparação tem o intuito de descobrir as regularidades, os deslocamentos e mudanças; elaborar modelos; identificar a continuação de pensamentos, além dos pontos próximos e distantes das teorias sociais.

Com isso, León e Garza (2014) classificam etapas do método comparativo, sendo elas: estruturação teórica para elaborar as hipóteses da comparação, determinar os critérios e fundamentar a comparação. Com base nas orientações dos autores, a pesquisa compara a economia ecológica e a Laudato Si': sobre o cuidado da casa comum para verificar os pensamentos similares e divergentes e refletir sobre os dez pontos comuns e um único divergente.

\section{Pontos semelhantes e distintos da economia ecológica e da Laudato Si’}

O estudo apresenta uma análise das teorias economia ecológica e a carta encíclica do papa Francisco Laudato Si': sobre o cuidado da casa comum com o propósito de alavancar os pontos semelhantes e distintos de ambas por considerar a relevância dos pensamentos em discussão de conscientização ecológica e sustentável. A partir dessa perspectiva, os pontos semelhantes são: 
1) Ambas as teorias criticam o otimismo de que a tecnologia soluciona todos os problemas ambientais.

2) A afirmação de que a ecologia é maior que a economia.

3) A existência dos sistemas abertos.

4) São contra o consumismo obsessivo.

5) Preocupam-se com os resíduos, por estes acarretarem um elevado nível de poluição.

6) Pensamentos contrários à guerra.

7) Incentivam o uso de energia solar.

8) Estimulam a sociedade a viver um amor fraterno.

9) Enfatizam novos hábitos à sociedade.

10) São a favor da sustentabilidade.

Ambas as teorias fornecem afirmações críticas à suposição de que a tecnologia soluciona qualquer problema ao meio ambiente. Papa Francisco (2015) considera a tecnologia como incapaz de solucionar todos os mistérios das interações vigentes entre as coisas, e ela pode até decifrar um problema, porém cria outros. May (2010) acrescenta que existem limites biofísicos das tecnologias prestados pela natureza.

Segundo Martinez-Allier (2015), a ecologia é finita e maior que o subsistema econômico, e o papa Francisco (2015) considera a economia como um ramo da ecologia integral, ou seja, tanto os pensadores da corrente economia ecológica quanto o sumo pontífice afirmam a grandeza da ecologia e que a economia é somente uma parte desse universo finito.

Outra afirmativa conjunta dos teóricos é a existência dos sistemas abertos. May (2010) afirma que a economia é formada por sistemas abertos. Cavalcanti (2010), por sua vez, ilustra a entrada de energia solar no sistema e a saída de energia dissipada. O papa Francisco (2015), por sua vez, relata que o universo é formado por vários sistemas abertos, os quais se comunicam entre si com diversas relações e participações.

Outro ponto específico da discussão de ambas as teorias é o consumismo obsessivo, o qual Georgescu-Roegen (2008) denomina de "doença do sentido humano", sendo necessária uma nova educação, para desprezar a compra em excesso. Papa Francisco (2015) declara o tema como reflexo da tecnociência e denuncia a falsa liberdade vivida pela maioria, uma vez que quem é realmente livre são os poderosos econômicos e financeiros. Bento XVI (2009) enfatiza que a compra é um moral, e além do aspecto econômico, ou seja, os consumidores são responsáveis socialmente por aquilo que compram.

A consequência do consumismo obsessivo é o descarte de resíduos ao planeta, os quais gradativamente aumentam o nível de poluição. Leff (2004) comenta que os resíduos do sistema produtivo não são problemas teóricos, porém apresentam realidades deploráveis na prática. Por exemplo, o papa Francisco (2015) chama atenção para as centenas de milhões de toneladas de 
resíduos anuais, que fazem com que o planeta se torne um depósito de lixo. O papa direciona a causa à cultura do descarte, que danifica a casa comum.

O próximo ponto em comum das teorias é a contrariedade à guerra, o sumo pontífice afirma que ela causa prejuízos graves à natureza e à cultura das nações; Georgescu-Roegen (2008), por sua vez, é a favor da proibição total da guerra e dos seus dispositivos de produção para que posteriormente os países libertem forças produtivas que contribuam com a ajuda internacional.

A proposta de energias renováveis é considerável entre ambas as teorias, no entanto a energia solar possui destaque por ser um recurso abundante (PAPA FRANCISCO, 2015). GeorgescuRoegen (2008) comenta a necessidade de a energia solar tornar-se costume à sociedade ou o controle da fusão termonuclear, para que, com cuidado regimentar, controle as perdas de energia.

Outra mudança necessária à sociedade é a inclusão do amor ao próximo, o papa Francisco (2015) enaltece o amor fraterno universal, mostrando uma preocupação com o outro, que acarreta os aspectos sociais, políticos e econômicos. Georgescu-Roegen (2008) propõe à sociedade uma nova ética, cujo mandamento principal seja amar a tua espécie como ama a ti mesmo, sendo uma forma de os indivíduos se preocuparem com as novas gerações.

Outro tema partilhado tanto pelo papa quanto pelos economistas ecológicos são as novas atitudes, tanto na parte de consumo quanto na conscientização da crise ecológica. $\mathrm{O}$ papa Francisco (2015) solicita às nações novas hábitos em relação ao consumo, pede aos jovens que sejam sensíveis à ecologia e defendam a natureza. Em contrapartida, Georgescu-Roegen (2008) cria o pensamento decrescimento econômico, ou seja, o inverso de crescimento, e Latouche (2009) acrescenta que a proposta é uma mentalidade passível de realidade e de evoluções, basta a humanidade ser contra o pensamento dominante de crescer por crescer economicamente.

Nesta perspectiva, uma sociedade sustentável é a solução para ambas as teorias. Lago (2013) afirma que a economia ecológica interpreta a sustentabilidade de uma maneira forte e entende o capital natural e a manufatura como bens complementares e cabíveis de preservação. O papa Francisco (2015) apela à proteção do planeta, com a ajuda das nações desenvolvidas, em promoção de uma vida sustentável às nações necessitadas, assim o desejo papal é a sustentabilidade para todos.

Contudo, a economia ecológica e a carta encíclica Laudato Si’: sobre o cuidado da casa comum apresentam um ponto contrário, que é a regulação da natalidade, crucial tanto para o "decrescimento econômico" de Georgescu-Roegen (2008) quanto para o estado estacionário de Daly (1991), os quais compreendem a necessidade de uma diminuição dos indivíduos para comportar o limite físico do planeta.

Em conformidade com os principais autores da economia ecológica, a Organização das Nações Unidas (ONU, 2019) declara que, em 2100, a população mundial atingirá a quantidade de 11 bilhões de habitantes, o auge de cidadãos no planeta Terra. Por exemplo, de acordo com Santos et al. (2018), a população brasileira somente irá reduzir a partir de 2043, ou seja, daqui a 20 anos aproximadamente. Por isso, com a constatação desses dados, Georgescu-Roegen (2008) e Daly (1991) projetam uma realidade trágica para o futuro da humanidade, caso o comportamento humano não se altere para o desenvolvimento sustentável. 
No entanto, ao papa Francisco (2015) somente interessa solucionar as dificuldades dos pobres e desejar uma sociedade melhor, e não se limitar à taxa de natalidade. $\mathrm{O}$ argumento do pontífice solidifica com a mentalidade do Pontifício Conselho "Justiça e Paz" (2010), ao compreender que o desenvolvimento integral é incluir as gerações futuras, com a consciência do bem para toda e qualquer geração de indivíduos, e regular a natalidade não significa esse desenvolvimento.

Por fim, o artigo apresenta as devidas conclusões com os dez pontos semelhantes e um tópico distinto entre a economia ecológica e a carta encíclica do papa Francisco compreendidas pelos autores. Verifica-se maior proximidade entre as teorias, entretanto o argumento crucial para os economistas ecológicos não é conveniente ao sumo pontífice por abordar um desenvolvimento integral distinto. Entre os assuntos equivalentes destaca-se o desejo dos teóricos por uma sociedade sustentável.

\section{Conclusão}

Segundo as análises descritas, verifica-se a relevância de ambas as teorias à conscientização da sociedade para a conservação do ecossistema, o sistema predominante econômico, político e social degrada a natureza em proporções catastróficas. Logo, a sociedade necessita responder às ameaças ecológicas urgentemente. A economia ecológica utiliza a Segunda Lei da Termodinâmica como forma de compreender a realidade econômica e, a partir da lei, formular soluções para uma vida sustentável. A carta encíclica Laudato Si': sobre o cuidado da casa comum, do papa Francisco (2015), acrescenta o conceito de ecologia integral com o intuito de alertar cristãos e não cristãos a entenderem o ecossistema não somente no contexto ambiental, mas em diversas dimensões.

As teorias convergem nos seguintes pontos: o otimismo de que a tecnologia soluciona todos os problemas ambientais; a ecologia é maior que a economia; existência de sistemas abertos; contrariedade ao consumismo obsessivo; preocupação com os resíduos; contrariedade à guerra; incentivo ao uso de energia solar; incentivo à sociedade para viver um amor fraterno; ênfase a novas atitudes dos indivíduos; e são a favor da sustentabilidade. No entanto, divergem no que diz respeito à regulação da natalidade.

Com isso, assinala-se maior proximidade entre a economia ecológica e a carta encíclica papal. O destaque dos pontos em comum é o fato de ambas serem a favor da sustentabilidade, dividida por Sachs (2004) nos pilares social, econômico, político, ambiental e territorial. O pilar social caracteriza-se por motivos intrínsecos e instrumentais; o econômico submete-se à viabilidade econômica; o pilar político determina a democracia e a concretização das ações; o ambiental evidencia duas grandezas: recipientes de resíduos e a vida como oriunda de bens. Por fim o pilar territorial, com requisitos de distribuição de serviços e bens para todos.

Porém, o único ponto distinto entre as teorias é o argumento crucial à economia ecológica. A regulação de natalidade é o único modo possível de usufruir satisfatoriamente dos bens e serviços ecossistêmicos sem uma redução drástica de nível de bem-estar social. Entretanto, o papa Francisco fundamenta-se na frase do Pontifício Conselho "Justiça e Paz" (2010), em que o aumento da população é conciliável com o desenvolvimento íntegro e solidário. Então, sugerem-se 
estudos voltados à teoria econômica e ao pensamento do sumo pontífice, para que posteriormente ambos caminhem em unidade e, consequentemente, uma sociedade mais humana e sustentável.

\section{Referências}

ADOÇÃO ACORDO DE PARIS. Conferência as Partes. Paris, 11 set. 2015. Disponível em: https:// nacoesunidas.org/wp-content/uploads/2016/04/Acordo-de-Paris.pdf. Acesso em: 1 nov. 2019.

ASSIS, M. C. de. Metodologia do trabalho científico. São Paulo: Atlas, 2009.

BÍBLIA Sagrada da Ave-Maria. [s.1.]: Edição Claretiana, 2015.

BOULDING, K. E. The economics of the coming spaceship Earth. In: JARETT, H. (Ed.). Environmental quality in a growing economy. Baltimore, MD: Resources for the Future: Johns Hopkins University Press, 1966.

CAMARGo, P. L. T. de. Valoração ambiental da Cachoeira da Serrinha (Parque Estadual do Itacolomi) Mariana/MG. 2014. 94 f. Dissertação (Mestrado em Sustentabilidade Socioeconômica Ambiental) - Universidade Federal de Ouro Preto, Ouro Preto.

CAVALCANTI, C. Concepções da economia ecológica: suas relações com a economia dominante e a economia ambiental. Estudos Avançados, v. 24, n. 68, 2010. Disponível em: http://www.scielo.br/scielo. php?script=sci_arttext\&pid=S0103-40142010000100007. Acesso em: 8 nov. 2019.

CECHIN, A. D.; VEIGA, J. E. da. A economia ecológica e evolucionária de Georgescu-Roegen. Revista de Economia Política, v. 30, n. 3, 2010. Disponível em: http://www.scielo.br/scielo.php?script=sci_arttext\&pid=S0101-31572010000300005. Acesso em: 8 nov. 2019.

CLAUSIUS, R. Théorie mécanique de la Chaleur. Paris: Éditions Jacques Gabay, 1865.

COSTANZA, R. et al. Goals, agenda and policy recommendations for ecological economics. In: COSTANZA, R. (Org.). Ecological economics: the science and management of sustainability. New York: Columbia University Press, 1991. p. 1-21.

DALY, H. Steady-State economics. 2nd. ed. Washington, DC: Island Press, 1991.

GEORGESCU-ROEGEN, N. O decrescimento - entropia, ecologia e economia. Lisboa: Instituto Piaget, 2008.

GEORGESCU-ROEGEN, N. The entropy law and the economic process. Cambridge: Harvard University Press, 1971.

LAGO, A. A. C. do. Conferências de desenvolvimento sustentável. Brasília, DF: FUNAG, 2013.

LATOUCHE, S. Pequeno tratado do decrescimento sereno. São Paulo: WMF Martins Fontes, 2009.

LEFF, E. Racionalidad ambiental: la reapropiación social de la naturaleza. Mexico, DC: Siglo XXI, 2004.

LEÓN, C. G. D. de; GARZA, E. A. L. de la. Método comparativo. Mexico, DC: Tirant Humanidades, 2014.

LESBAUPIN, I. Para salvar a humanidade do desastre ecológico. Fronteiras, Recife, v. 2, n. 1, p. 98-117, 2019. 
MARTINEZ-ALLIER, J. Ecological economics. In: WRIGHT, J. D. (Ed.). Internacional Encyclopedia of the Social and Behavioral Sciences. Amsterdam: Elsevier, 2015.

MAY, P. H. Economia do meio ambiente: teoria e prática. 2. ed. Rio de Janeiro: Elsevier, 2010.

MILL, J. S. Principles of political economy. Londres: Longmans, 1920.

MOTA, J. A. O valor da natureza: economia e política dos recursos naturais. Rio de Janeiro: Garamond, 2006.

MURAD, A. Laudato Si e Ecologia Integral. Um novo capítulo da Doutrina Social da Igreja. Medellín, v. 43, n. 168, 2017. Disponível em: http://documental.celam.org/medellin/index.php/medellin/article/ view/183. Acesso em: 5 nov. 2019.

NASCIMENTO, E. P. Trajetória da sustentabilidade: do ambiental ao social, do social ao econômico. Estudos Avançados, v. 26, n. 74, 2012. Disponível em: http://www.scielo.br/scielo.php?pi$\mathrm{d}=\mathrm{S} 010340142012000100005 \&$ script $=$ sci_abstract\&tlng=pt. Acesso em: 8 nov. 2019.

OLIVEIRA, W. de F.; ANDRADE, D. C. Economia ecológica, capitalismo e crises econômicas. Revista Sociedade Brasileira Economia Política, São Paulo, n. 33, p. 73-101, 2012. Disponível em: https:// www.researchgate.net/publication/259221325_Economia_Ecologica_capitalismo_e_crises_economicas. Acesso em: 8 nov. 2019.

ORGANIZAÇÃO DAS NAÇÕES UNIDAS - ONU. População mundial deve ter mais 2 bilhões de pessoas nos próximos 30 anos. ONU News, 17 jun. 2019. Disponível em: https://news.un.org/pt/ story/2019/06/1676601. Acesso em: 3 abr. 2021.

PAPA BENTO XVI. Carta Encíclica Caritas in Veritate. São Paulo: Paulinas, 2009.

PAPA FRANCISCO. Carta Encíclica Laudato SI': sobre o cuidado da casa comum. São Paulo: Paulinas, 2015 .

PONTIFÍCIO CONSELHO "JUSTIÇA E PAZ". Compêndio da doutrina social da igreja. São Paulo: Paulinas, 2010.

REZENDE, Vani Terezinha de. Laudato Si', Ecologia e Sustentabilidade. Revista Relicário, v. 3, n. 5, p. $1-4,2016$.

RICARDO, D. The works and correspondence of David Ricardo. Cambridge: Cambridge University Press, 1951.

ROBBINS, L. On a certain ambiguity in the conception of stationary equilibrium. Economic Journal, v. 40, p. 194-214, 1930.

ROMEIRO, A. R. Economia ecológica e valoração da natureza. Leituras de Economia Política, n. 21, 2014.

ROPKE, I. Trends in the development of ecological economics from the late 1980s to the early 2000s. Ecological Economics, v. 55, n. 2, p. 262-290, 2005. Disponível em: https://www.sciencedirect.com/ science/article/pii/S0921800904004173. Acesso em: 8 nov. 2019.

SACHS, I. Desenvolvimento: includente, sustentável, sustentado. Rio de Janeiro: Garamond, 2004.

SAES, B. M. Macroeconomia ecológica: o desenvolvimento de abordagens e modelos a partir da economia ecológica. 2013. 144 f. Dissertação (Mestrado em Desenvolvimento Econômico) - Universidade Estadual de Campinas, Campinas. 
SANTOS, F. O. dos; MALTA, S. M. C.; FARIA, C. de O. Sobre um modelo de crescimento para a população do Brasil. Proceeding Series of the Brazilian Society of Applied and Computational Mathematics, v. 6, n. 1, 2018. Trabalho apresentado no XXXVII CNMAC, S.J. dos Campos - SP, 2017. Disponível em: https://proceedings.sbmac.org.br/sbmac/article/viewFile/1951/1969. Acesso em: 3 abr. 2021.

SANTOS, I. A. Economia ecológica e políticas públicas: um olhar sobre o Cerrado Brasileiro. 2018. 98 f. Dissertação (Mestrado em Economia) - Universidade Federal de Uberlândia, Uberlândia.

SCHNEIDER, S.; SCHIMITT, C. J. O uso do método comparativo nas ciências sociais. Cadernos de Sociologia, Porto Alegre, v. 9, p. 49-87, 1998.

SILVEIRA, G. dos S. Política e religião: a Encíclica Laudato Si’ sob análise do discurso. 2018. 94 f. Dissertação (Mestrado em Ciências das Religiões) - Faculdade Unida da Vitória, Vitória.

TAVARES, S. S. Amazônia(s): permanente colonialidade versus ecologia integral. Fronteiras, Revista de Teologia da UNICAP, v. 2, n. 1, 2019. Disponível em: http://www.unicap.br/ojs/index.php/fronteiras/ article/view/1377. Acesso em: 5 nov. 2019.

THOMASSET, A. Uma necessária conversão para uma "Ecologia Integral!". Fronteiras, Revista de Teologia da UNICAP, v. 2, n. 1, 2019. Disponível em: http://www.unicap.br/ojs//index.php/fronteiras/ article/view/1397. Acesso em: 5 nov. 2019.

VAN DEN BERGH, J. Environment versus growth - a criticismo of "degrowth" and a plea "a-growth". Ecological Economics, v. 70, p. 881-890, 2011.

VEIGA, J. E. da. Indicadores de sustentabilidade. Estudos Avançados, v. 24, n. 68, 2010. Disponível em: http://www.scielo.br/scielo.php?script=sci_arttext\&pid=S0103-40142010000100006. Acesso em: 8 nov. 2019.

WALLSTRÖM, M. Discurso "From words to deeds. The results of the sustainability summit in Johannesburg", 11 de setembro de 2002, comentado pelo Telegrama 883 de Braseuropa, de 13 desetembro de 2002. 
